\title{
Entrelacs
}

Cinéma et audiovisuel

18 | 2021

Laurent Roth, cinéaste

\section{Poésie du seuil}

Laurent Roth

\section{OpenEdition}

Journals

Édition électronique

URL : https://journals.openedition.org/entrelacs/6192

DOI : 10.4000/entrelacs.6192

ISSN : 2261-5482

Éditeur

Éditions Téraèdre

Référence électronique

Laurent Roth, «Poésie du seuil », Entrelacs [En ligne], 18| 2021, mis en ligne le 15 novembre 2021, consulté le 14 décembre 2021. URL : http://journals.openedition.org/entrelacs/6192 ; DOI : https:// doi.org/10.4000/entrelacs.6192

Ce document a été généré automatiquement le 14 décembre 2021.

Tous droits réservés 


\title{
Poésie du seuil
}

\author{
Laurent Roth
}

\section{Sous le Seuil}

1 Je livre ici dix petits poèmes qui témoignent du mystère du seuil. De la frayeur dont nous portons l'empreinte, de la frayeur, au franchissement de sa limite. Le sol se retire - perte des notions communes - et la pierre du temple s'érige - feu, feu de la langue sacrée. Le terrain nu de la prose est bêché au plus près, vers le fond des eaux de la terre. La parole nue du désert est bêchée, parfois l'embellie du jaillissement.

2 Du désert immobile, il me fallait toucher cette limite : là où les mots perdent connaissance. Or les mots, aujourd'hui, se connaissent bien, ils se connaissent dans la science de la langue. Dans la science, ils ont honte de désigner quelque chose. Ils sont, eux-aussi, tombés sous la loi, infinie, de l'échange. Le commerce du signe a augmenté leur performance. Mais ils en sont morts. Poétiquement morts.

3 Dans le vide et la dépossession, le poète et le philosophe ont inventé un nouvel état du verbe. Il a pour nom le visible. Son programme est : s'extirper de la tyrannie du dire. Car la vision précède les mots, elle les provoque, elle fait nous arriver les choses sans souci du sens. Elle ne connaît pas cette débilité de l'axiome, cette terreur d'être autorisé dont souffrent les humains. Oui, les laisser être, ces choses, se laisser aller au danger de leur trace!

4 Poème en prose est ce corps mystique, ce petit corps paradoxal qui assume, par les mots, de laisser les choses être, en dehors des mots. C'est le corps du mystère, il donne la présentation première, littéralement sublime, sous le seuil. Il y a la frayeur qui scelle en nous le lieu du passage. Le fleuve y passe en effet. Il mène au chiffre gravé au fond $\mathrm{du}$ visible, au fond où notre corps même repose. Le fleuve coule au pied des temples, il coule par-delà les fronts et la mémoire. Au fond gît le poème qui ne garde du monde que ce qui se dépose.

5 Laurent Roth, 1984. 


\section{Le Bateleur}

Il y aurait le commencement. Une histoire. Les cours de Paris, les vitrines qui regardent. Le désir. Une gigantesque tauromachie aux dents blanches.

Des falaises blanches et aveugles qui tournoient, poudroient et frémissent jusqu'au drapeau là-bas, sein bleu, blanc et rouge, gonflé du ciel.

La douche de lumière à travers les jalousies. La pointe des odeurs, la chair abattue sous le corsage des triperies-volailles.

Le train cahotant des auvents de toile, les portes soufflets-courts.

Des couloirs, les arrière-sols, d'autres portes qui battent la semelle.

Ce serait l'histoire commencée, avec le malaise d'être - le malaise de l'horizon en moins.

\section{Le Parvis}

J'entends bruisser les arbres derrière les grilles d'or. C'est l'automne et mes yeux se lèvent vers de terrestres altitudes de marbre. Les arbres pivotent. Les fûts des colonnes se rejoignent haut dans le ciel et les tapis rouges s'élèvent par saccades. C'est le paradis.

La maîtresse de maison m'attend juchée sur des talons de cristal. Un cartel aligne sept coups. Elle ouvre le cortège en faisant craquer des pétales d'angélique, jusque sous les plafonds. C'est le ravage des incendies, les fauves sont lâchés dans les vitrines.

Je vois, dans une galerie historique, des vitriers sur des échelles qui dessinent des monogrammes.

La reine est morte!

\section{Nommer la Mer}

Sous les palmiers viennent s'échouer les contours. Une aube s'annonce et la plage est confuse. Les vagues y déposent le bleu, sans pareil, à l'image de la mer, sans nom. Il y a des frémissements.

L'ardeur monotone de la mer. Les palmiers : soleil fixé, vaste éternuement d'hélice. Les heures sans contours : ennui brassé sans mesure. Les vagues et les coquillages, la dispersion des signaux de mer, creux en eux-mêmes, et bleus surtout, sans pareil, dessinant le nom et le monogramme.

Car c'était la mer. La mer dans le nom, le monogramme et la proclamation, l'immense bête égale à elle-même et nos départs neufs dans la monotonie.

Oui, le nom, la vogue et la galère !

Les plages ont tourné. Sur les ponts de planche les hommes font le commerce des élingues, des vergues et des misaines, ils peignent la géante. Ils touchent son grand corps bleu avec des mots.

Et le technique conjure l'océan.

\section{IIII. La Cathédrale}

La base étroite et le sommet très large. Les piliers qui s'écartent et les ogives qui bandent. C'est l'église. Les arcs des travées qui pointent très haut sous les voûtes, le grand vertige parabolique. C'est la grande assemblée des pierres, c'est l'église. Les colonnes en liesse sous leurs jupes de verre, la joie dans le seigneur, la sagaie dans l'hostie, oui, tous les membres sont ivres, c'est l'église, et le grand corps de Dieu...

\section{Le Vitrail}

Du fond du chœur, c'est comme si les choses déteignaient sur les mots. 
Il y a là une chapelle où des grilles maillent les couleurs. Aux heures hautes du jour nagent les reflets roses d'un vitrail. Un filet de plomb s'abat sur les eaux vives, un filet d'ombre serre des poissons d'or.

Ce sont les grilles d'une chapelle.

En dessinant des rinceaux sur le sol, elles égrènent, entre l'empattement d'une tige, le délié d'une feuille, le pollen des couleurs. Marie, sa grenade, le lys de Joseph, vient saigner la pierre ou blanchir un tombeau.

Ce sont les grilles d'une chapelle, leur portée suspend les notes bleues de mon cœur. Des musiques. Les dalles chantent, la chair flotte, par les grilles le vitrail se recompose. Il repose sur le métier du jour, tissu mystique, impalpable, changeant, à l'image de la mer sans nom.

Et les grilles, dans leur infini chantournement, poursuivent son chiffre mystérieux.

\section{La Maison}

La femme est le milieu. L'Être l'habite. Son silence prélude à la musique.

Sur les murs de la maison, des miroirs et des fenêtres. Les tapis et les tableaux sont perchés dans la lumière. Un chat s'incruste sur le seuil, sentinelle de la vision. Et la femme se penche, son crâne plein de rêves.

Du dehors, d'autres harmonies. La rue réverbère le temps : conversations, gammes et jeux d'enfant tissent l'étoffe du jour. La sirène du port fait refluer le silence. Et sur l'acajou des tables, le murmure indécis des soupières.

La femme s'est refermée sur moi. J'habite un lieu qui est silence. De son œil rond, le chat digère le monde. J'habite un lieu qui est musique. Dans la maison, les choses sont en prière. J'habite un lieu est qui présence.

$\mathrm{J}$ 'habite la femme, elle est toute mon église.

\section{La Porte-fenêtre}

\section{Sur Pierre Bonnard}

Ce n'est ni l'intérieur, ni l'extérieur. C'est le jour et la nuit. C'est le temps légendaire de toute lisière.

$\mathrm{Au}$ seuil de la porte-fenêtre, les choses échangent les ondes et les couleurs. Un oiseau bruit dans le papier à fleurs. Un fauteuil s'arrondit sous le hêtre. Dans la chambre, parmi les mauves, le miroir songe et les choses s'animent. Du jardin, de l'œil, du miroir, comment maintenant faire la part?

Voici qu'à l'intérieur les objets se relèvent. La baignoire sombre et les femmes rosissent. Les chaises, les chats, les demi-porcelaines s'avancent vers nous. Tout se relève devant la vision, et c'est déjà la vision: salut des choses, choses révélées, le carrelage est la moire et la moire la pelouse au soleil.

Plus tard disparaît la porte-fenêtre - adieu au cadre matériel. La vision fait de tout sa nature et l'eau, cette pluie intérieure, ruisselle dans les choses. Parfois l'œil d'un poète, dont l'onde emporte nageurs et rameaux en fleurs, ressource le fleuve. Au loin la mer est bleue, il crée dans le rythme et les affections.

\section{Le Faux-Pas}

\section{Sur Antoine Watteau}

Il y a la rencontre d'amour et les amours de rencontre, selon qu'à l'infini l'amour se mêle, ou que les délices finissent à l'absence. Le ruisseau serpente et le pas est étroit. Le couple s'avance. De la pression d'une main sur une main naît un ciel au cœur de l'homme, qui tremble et s'évanouit dans un reflet. 
Parcs et châteaux. Au colin-maillard du désir, le couple est fait, défait, le temps d'un pas, à prendre et perdre pied dans le vide. Le royaume a été, sera, entre lui et lui quelque chose se tient entre - est-ce l'eau, est-ce le ciel ? - comme un fantôme de commencement.

L'homme piétine sur le seuil et transporte l'amante : jardins fabuleux, horizons immenses. Le pas franchi est si grand, on se croirait perdu. Mais seuls les caprices de la mode occupent les conversations, encore et encore, jusqu'à ce que l'ombre noircisse le dessous des forêts.

Voici le départ. Un froissement de satin se perd dans le silence. La relève-t-il ? Le repousse-t-elle? L'aventure est dans les mains qui cherchent les mains sous l'astre nocturne, dans les griffes au colin-maillard du désir, dans une nuque blanche, qui passe et disparait.

Un manteau rouge et des roses resteront sur la rive.

\section{VIIII. L'Hermite}

C'est l'histoire de l'aveugle. Un aveugle a toujours besoin d'une lanterne. Il a détourné ses yeux de la laideur du monde pour aller par les pays et les clartés.

Tenant son phare à hauteur de rêve, il est seul. Ses pieds ne fréquentent pas le sol, concret et doré comme la mort. Il tient son bâton de chair en travers de sa route, sa pèlerine est si lourde qu'elle l'empêche d'avancer.

L'aveugle est un voyageur de l'âme. Il avance dans le labyrinthe des songes. Patiemment, il accomplit sa traversée nocturne. Pour celui qui l'accueille - le véritable fantôme -, sa lanterne semble rougie, opaque : c'est pour lui seul qu'elle déroule son manège de féeries.

Quand soi-même on s'est mis en chemin, avec les poètes et autres voyageurs, on rencontre cet Hermès au terme de la route. Sage comme une image, il en est passé maître. Au plus fort de la nuit, il se cache dans la lumière, devenue.

\section{La Roue et la Fortune}

Le bateleur, devant le spectacle des portes et des falaises, n'avait aucune idée du commencement. La crainte naquit au parvis des châteaux en deuil. Des voyages, des voyages, pour dompter l'espace, refouler l'ennui.

C'est dans les tresses des pierres que se cachait l'amante : son visage enfoui dans la lumière, penché sur une maison où les chats nagent entre le bleu et l'hiver.

Puis il y eut le saut dans le vide lors d'une garden-party, un faux-pas, et voici, on se retrouve à mi-parcours, poussant son destin comme un amoncellement de neiges.

\section{RÉSUMÉS}

Laurent Roth livre ici dix petits poèmes inédits extraits - du recueil Poésie et peinture (1984) - qui témoignent du mystère du seuil.

Laurent Roth delivers here ten small unpublished poems - from the collection Poésie et peinture (1984) - which bear witness to the mystery of the threshold. 


\section{AUTEUR}

\section{LAURENT ROTH}

Après des études de philosophie, Laurent Roth profite de son service militaire en 1986 au sein de l'établissement cinématographique et photographique des armées pour réaliser Les Yeux brûlés un film qui est sorti en salles en 2015, après sa sélection au festival de Cannes, dans la section Cannes Classics. Suivront de nombreux courts et moyens métrages primés dans de grands festivals que La Huit a réunit dans un coffret paru en 2019. Depuis les années 2000, parallèlement à une activité d'écriture pour l'opéra et le théâtre, Laurent Roth poursuit son exploration des passerelles entre fiction et documentaire par une série de "fantaisies documentaires », selon ses termes, où il interprète son propre personnage comme dans Une maison de famille (2004), J'ai quitté l'Aquitaine (2005) ou L'Emmuré de Paris (2021), son premier long métrage actuellement en postproduction. Laurent Roth est également scénariste et a collaboré à l'écriture des films de JeanDaniel Pollet, Vincent Dieutre, Dominique Cabrera ou encore Stéphane Batut. Comme critique de cinéma, il a notamment travaillé aux Cahiers du cinéma et pour France culture. Il a publié une centaine d'articles et d'essais, ainsi que deux livres consacrés à Abbas Kiarostami et à Chris Marker. Enfin, Laurent Roth a également été pendant plusieurs années producteur au sein de la société Inthemood et directeur artistique de festivals (Festival International du documentaire « Fictions du réel » à Marseille, Ciné-citoyen à Paris). 